\title{
Front Matter: Volume 9622
}

, "Front Matter: Volume 9622," Proc. SPIE 9622, 2015 International Conference on Optical Instruments and Technology: Optoelectronic Imaging and Processing Technology, 962201 (5 August 2015); doi: $10.1117 / 12.2208364$

SPIE Event: International Conference on Optical Instruments and Technology 2015, 2015, Beijing, China 


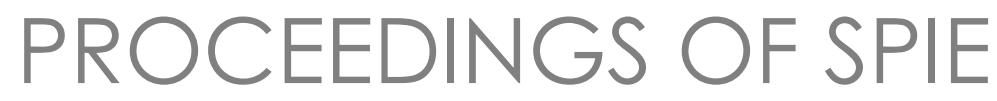

\title{
2015 International Conference on Optical Instruments and Technology
}

\section{Optoelectronic Imaging and Processing Technology}

\author{
Guangming Shi \\ Xuelong Li \\ Bormin Huang \\ Editors
}

17-19 May 2015

Beijing, China

Sponsored

CIS - China Instrument and Control Society (China)

SPIE

Published by

SPIE 
The papers included in this volume were part of the technical conference cited on the cover and title page. Papers were selected and subject to review by the editors and conference program committee. Some conference presentations may not be available for publication. The papers published in these proceedings reflect the work and thoughts of the authors and are published herein as submitted. The publisher is not responsible for the validity of the information or for any outcomes resulting from reliance thereon.

Please use the following format to cite material from this book:

Author(s), "Title of Paper," in 2015 International Conference on Optical Instruments and Technology: Optoelectronic Imaging and Processing Technology, edited by Guangming Shi, Xuelong Li, Bormin Huang, Proceedings of SPIE Vol. 9622 (SPIE, Bellingham, WA, 2015) Article CID Number.

ISSN: 0277-786X

ISBN: 9781628418033

Published by

SPIE

P.O. Box 10, Bellingham, Washington 98227-0010 USA

Telephone +1 3606763290 (Pacific Time) · Fax +1 3606471445

SPIE.org

Copyright (c) 2015, Society of Photo-Optical Instrumentation Engineers.

Copying of material in this book for internal or personal use, or for the internal or personal use of specific clients, beyond the fair use provisions granted by the U.S. Copyright Law is authorized by SPIE subject to payment of copying fees. The Transactional Reporting Service base fee for this volume is $\$ 18.00$ per article (or portion thereof), which should be paid directly to the Copyright Clearance Center (CCC), 222 Rosewood Drive, Danvers, MA 01923. Payment may also be made electronically through CCC Online at copyright.com. Other copying for republication, resale, advertising or promotion, or any form of systematic or multiple reproduction of any material in this book is prohibited except with permission in writing from the publisher. The CCC fee code is 0277-786X/15/\$18.00.

Printed in the United States of America.

Publication of record for individual papers is online in the SPIE Digital Library.

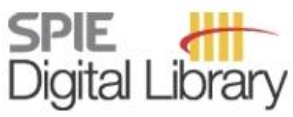

SPIEDigitalLibrary.org

Paper Numbering: Proceedings of SPIE follow an e-First publication model, with papers published first online and then in print. Papers are published as they are submitted and meet publication criteria. A unique citation identifier (CID) number is assigned to each article at the time of the first publication. Utilization of CIDs allows articles to be fully citable as soon as they are published online, and connects the same identifier to all online, print, and electronic versions of the publication. SPIE uses a six-digit CID article numbering system in which:

- The first four digits correspond to the SPIE volume number.

- The last two digits indicate publication order within the volume using a Base 36 numbering

system employing both numerals and letters. These two-number sets start with 00, 01, 02, 03, 04, $05,06,07,08,09,0 A, 0 B \ldots$ OZ, followed by 10-1Z, 20-2Z, etc.

The CID Number appears on each page of the manuscript. The complete citation is used on the first page, and an abbreviated version on subsequent pages. 


\title{
Contents
}

\author{
vii Authors \\ ix Symposium Committee \\ xi Conference Committee \\ xiii Introduction \\ xv Conference Sponsors
}

\section{SESSION 1 IMAGING QUALITY EVALUATION AND IMPROVEMENT}

962202 Spatial difference shaping to improve range resolution in 3D super resolution range-gated imaging [9622-7]

962203 Color enhancement and image defogging in HSI based on Retinex model [9622-74]

962204 Measurement of nano-particle diffusion in the simulated dynamic light scattering by contrast of dynamic images [9622-99]

962205 Hybrid phase retrieval from a single defocused image [9622-105]

962206 The $L_{\infty}$ constrained global optimal histogram equalization technique for real time imaging [9622-72]

\section{SESSION 2 NOVEL IMAGING TECHNIQUES}

962207 Compressive spectral imaging systems based on linear detector [9622-24]

962208 Evaluation of a single-pixel one-transistor active pixel sensor for low-dose indirectconversion x-ray imaging [9622-31]

962209 Terahertz polarization imaging based on the continuous wave terahertz radiations [9622-40]

$96220 \mathrm{~A}$ CS-based fast ultrasound imaging with improved FISTA algorithm [9622-50]

\section{SESSION 3 PATTERN RECOGNITION}

9622 OB A hyperspectral classification method based on experimental model of vegetation parameters and C5.0 decision tree of multiple combined classifiers [9622-10]

$96220 \mathrm{C}$ Turbulence mitigation and moving object detection for underwater imaging [9622-34] 
9622 OD The lucky image-motion prediction for simple scene observation based soft-sensor technology [9622-35]

9622 OE In-situ defect detection systems for R2R flexible PV barrier films [9622-67]

9622 OF Multi-patch matching for person re-identification [9622-81]

\section{SESSION 4 SYSTEM DESIGN AND APPLICATIONS}

$96220 \mathrm{G}$ Transmissive diffractive membrane optic for large aperture lightweight optical telescope [9622-27]

$9622 \mathrm{OH}$ A depth camera for natural human-computer interaction based on near-infrared imaging and structured light [9622-28]

$962201 \quad$ Night vision imaging system design, integration and verification in spacecraft vacuum thermal test [9622-32]

9622 0J Polarization information processing and software system design for simultaneously imaging polarimetry [9622-45]

9622 OK Indoor integrated navigation and synchronous data acquisition method for Android smartphone [9622-85]

$9622 \mathrm{OL} \quad$ Non-contact real-time heart rate measurements based on high speed circuit technology research [9622-97]

\section{SESSION 5 REMOTE SENSING AND WEAPONS}

$96220 \mathrm{M}$ Realization of video electronics system in the space-borne multispectral imager [9622-11]

$96220 N$ Research on the zoom range of liquid-solid composite lens [9622-70]

962200 Algorithm design for a gun simulator based on image processing [9622-86]

9622 OP Visual pattern degradation based image quality assessment [9622-54]

POSTER SESSION

$96220 Q$ Design and realization of an AEC\&AGC system for the CCD aerial camera [9622-1]

9622 OR Remote weapon station for automatic target recognition system demand analysis [9622-3]

9622 OS Design and realization of an image mosaic system on the CCD aerial camera [9622-6]

9622 OT Depth map super resolution and edge enhancement by utilizing RGB information [9622-17] 
9622 OU A novel track-before-detect algorithm based on optimal nonlinear filtering for detecting and tracking infrared dim target [9622-21]

9622 OV Real-time implementation of SIFT feature extraction algorithms in FPGA [9622-22]

9622 OW Defection technology of polarization target based on curvelet transform in turbid liquid [9622-25]

9622 0X A stereo matching method for actual binocular system [9622-26]

9622 OY Study of target tracking techniques based on non-scanning imaging lidar [9622-30]

$96220 Z$ Tracking and registration method based on vector operation for augmented reality system [9622-37]

962210 Temporal high-pass non-uniformity correction algorithm based on grayscale mapping and hardware implementation [9622-39]

962211 Design and recognition of three-dimensional calibration target based on coded marker [9622-42]

962212 Quantitative analysis of alteration mineral content and characteristic spectra of Hyperion image at oil and gas microseepage area [9622-61]

962213 ECG signals denoising using wavelet transform and independent component analysis [9622-65]

962214 Targets detection in smoke-screen image sequences using fractal and rough set theory [9622-68]

962215 The correction of the distortion of human face based on three-dimensional modeling methods [9622-76]

962216 Linear Bregman algorithm implemented in parallel GPU [9622-77]

962217 Camouflage target reconnaissance based on hyperspectral imaging technology [9622-78]

962218 Fast resolving of the nonconvex optimization with gradient projection [9622-79]

962219 A perceptual preprocess method for 3D-HEVC [9622-80]

96221 A Preliminary results of centroiding experiment for the STEP mission [9622-87]

9622 1B Automated seamline detection along skeleton for remote sensing image mosaicking [9622-91]

9622 1C Fast sub-pixel accuracy stereo image matching based on disparity plane [9622-101]

9622 1D Measurement of PSF for the extended depth of field of microscope based on liquid lens [9622-103] 
$96221 \mathrm{E}$ Wavefront correction in the active imaging system based on spatial heterodyne detection [9622-104]

9622 IF Remote sensing image registration algorithm based on circle correlation [9622-110]

$96221 G$ Perceptual image quality in normalized LOG domain for adaptive optics image postprocessing [9622-112] 


\section{Authors}

Numbers in the index correspond to the last two digits of the six-digit citation identifier (CID) article numbering system used in Proceedings of SPIE. The first four digits reflect the volume number. Base 36 numbering is employed for the last two digits and indicates the order of articles within the volume. Numbers start with 00, 01, 02, 03, 04, 05, 06, 07, 08, 09, OA, OB...0Z, followed by 10-12, 20-2Z, etc.

An, Ping, OT

Anavatti, Sreenatha G., OC

Bai, Tingzhu, Ol

Benlefki, Tarek, OF

Bian, Xiaoning, $\mathrm{OZ}$

Bird, D., OE

Blunt, L., OE

Boubekeur, Mohamed Bachir, OF

Cao, Yang, $1 \mathrm{~A}$

Cao, Yinan, 02

Chen, Bo, $1 \mathrm{E}$

Chen, Ding, $1 \mathrm{~A}$

Chen, Jianyu, $1 \mathrm{~B}$

Chen, Jun, 08

Chen, Kuo, 15

Chen, Sui, OY

Chen, Xiaomei, 12

Cheng, Ganglin, OM

Dong, Bing, 05

Dong, Liquan, OL, 13

Duan, Jin, OW

Edge, S., OE

Elrawemi, M., OE

Fan, Songtao, 02

Feng, Bing, $O Q$

Feng, Huajun, 15

Fu, Qiang, OW

Gao, F., OE

Gao, Han, 03

Gao, Kun, OB, OU

Gao, Weizhe, $1 G$

Gao, Yanfei, $\mathrm{OZ}$

Gong, Xuemei, OB

Gong, Zhe, ol

Gu, Dalong, 11

Gu, Guo-hua, OV

Guo, Shiping, $1 G$

Guo, Tong, 17

Habib, Ayman, OK

Halder, Kalyan K., OC

Han, Lu, OU

Han, Peng, 04

Han, Tingyu, OA

He, Yugao, OA

Hollis, P., OE

$\mathrm{Hu}, \mathrm{Bin}, \mathrm{OD}$

Hu, Chunsheng, OK

Hua, Wenshen, 17

Huang, Jing, OM
Huang, Qiang, ON

Hui, Mei, OL, 13

Jia, Genglei, 05

Jiang, Nan, $1 \mathrm{C}$

Jiang, X., OE

Jiao, Jianchao, OG

Jiao, Yang, 06

Jin, Jiangao, OG

Jin, Minglei, 10

Jin, Weiqi, 0J, 10

$\mathrm{Ke}, \mathrm{Jun}, 03,00,16$

Kong, Lingqin, $\mathrm{OL}$

Labidi, Hocine, OF

Lei, Ning, OM

Lei, Zhang, OR

Li, Baoquan, IA

Li, Haitao, IA

Li, Huan, 07

$\mathrm{Li}$, Jisheng, $1 \mathrm{G}$

Li, Leida, OP

Li, Ligang, $1 \mathrm{~A}$

Li, Pengyan, 16

Li, Qi, 15

Li, Qianqian, 12

Li, Sheng-cai, OR

Li, Shuo, 10

Li, Xiaoyang, OY

$\mathrm{Li}$, Xiaoyang, $1 \mathrm{E}$

Li, Xiyuan, Ol

Li, Yan, OD

Li, Yan, OQ, OS

$\mathrm{Li}$, Yiyang, 10

Li, Youfu, 02

Li, Yueping, $1 \mathrm{C}$

Lin, Jie, OA

Lin, Juan, $O B$

Lin, Weisi, OP

Liu, Changhai, $1 G$

Liu, Hai ying, $O Q, O S$

Liu, $\mathrm{HaO}, \mathrm{OH}$

Liv, Jing, OJ

Liu, Lin, 06

Liv, Manjin, 13

Liu, Ming, OL, 13

Liu, $\mathrm{Na}, 12$

Liv, Xiaohua, OL

Liu, Xiaoquan, 02

Liv, Xin, 1B

Liu, Xinghui, 08 
Liu, Xun, 17

Liv, Yanli, 07

Liv, Ying, 09

Liu, Ying, OB, OU

Liu, Yu, $0 \mathrm{O}$

Liv, Yue, $\mathrm{OH}$

Lu, Dezhen, 02

Lu, Kai-li, OV

Luo, Kaiqing, 04

Luo, Sen-Lin, OF

Ma, Wanzhuo, OW

Muhamedsalih, H., OE

Niu, Yi, 06, 18

Ou, Hai, 08

Pei, Yifei, 0

Peng, Zhong, OY

Qian, Wei-xian, OV

Qin, Shiqiao, OK

Qiu, Jian, 04

Qu, Yufu, 1C, 1D

Ren, Qiongwei, 06

Rong, Peng, OM

Shan, Bin, OY

Shang, Yonghong, 0

Shao, A-jun, OV

Shen, Fangfang, 18

Shen, Yanchun, 09

Shi, Cai, OR

Shi, Cong, OL

Shi, Guangming, 06, OA, OP, 18

Shi, Yawen, 19

Song, Xiuping, ON

Su, Yun, OD, OG

Sui, Dong, 16

Tahtali, Murat, OC

Tang, D., OE

Tian, Yuexin, OU

Wan, Wenfei, OP

Wang, Baohua, OG

Wang, Hengyou, $\mathrm{OZ}$

Wang, Jing, Ol

Wang, Kai, 08

Wang, Liqiang, $\mathrm{OH}, \mathrm{OX}$

Wang, Meng, OB

Wang, Peng, OQ, OS

Wang, Qianqian, OY

Wang, Rui, 05

Wang, Ruisheng, OK

Wang, Xingshu, OK

Wang, Xinwei, 02

Wang, Yahui, OJ

Wang, Yongfang, 19

Wang, Yubing, 19

Wei, Hao yun, $0 Q$

Wei, Ping, 03, 00, 16

Wei, Wenjian, OK

Wen, Renjie, OJ

Wu, Jinjian, $O P$

Wu, Jizhe, OL
Wu, Xiaobin, 04

Xie, Tianhua, $1 \mathrm{~F}$

$X i n$, Jianguo, ON

Xiong, Wei, 11

$\mathrm{Xu}$, Zhihai, 15

Xue, Yujia, ID

Yan, Xiaoke, 14

Yan, Xu-le, OT

Yang, Changaing, $1 \mathrm{~F}$

Yang, $X U, 1 E$

Ye, Qingmin, 15

You, Zhixiang, OT

Yuan, BO, $\mathrm{OH}, \mathrm{OX}$

Zeng, Luan, 11

Zhai, You, 11

Zhan, Juntong, OW

Zhang, Hansong, 1B

Zhang, Rongzhi, IG

Zhang, Shao jun, OS

Zhang, Shuhao, OY

Zhang, Su, OW

Zhang, Yue, OG

Zhao, Guanghui, 18

Zhao, Guozhong, 09

Zhao, Haibo, 07

Zhao, Yuejin, OL, 13

Zhao, Zhu, 13

Zhen, Haijing, 0 l

Zheng, Shuai, OT

Zhong, Xiaoming, 07

Zhou, Tingting, $0 \mathrm{X}$

Zhou, Yan, 02

Zhu, Hai bin, OS

Zhu, Shenyu, 1D

Zou, Jianhua, IG

Zuo, Yi-fan, OT 


\title{
Symposium Committee
}

\author{
General Chairs
}

Tianchu Li, National Institute of Metrology (China)

Toyohiko Yatagai, Utsunomiya University (Japan)

Conference Co-chairs

Yuri Chugui, New Siberia Academy of Sciences (Russian Federation)

Arthur Chiou, National Yang-Ming University (Taiwan, China)

Songlin Zhuang, Shanghai University of Science and Technology (China)

Liwei Zhou, Beijing Institute of Technology (China)

Shenghua Ye, Tianjin University (China)

Yimo Zhang, CIS/Tianjin University (China)

Zheng You, Tsinghua University (China)

Guangjun Zhang, Beihang University (China)

Technical Program Chair

Guofan Jin, Tsinghua University (China)

Technical Program Co-chairs

Jinxue Wang, Raytheon Company (United States)

Tiegen Liu, Tianjin University (China)

Local Organizing Committee Chair

Youhua Wu, China Instrument and Control Society (China)

Local Organizing Committee Co-chairs

Guoqiang Ni, Beijing Institute of Technology (China)

Jianqiang Zhu, Shanghai Institute of Optics and Fine Mechanics, CAS (China)

Daoyin Yu, Tianjin University (China)

Yanbiao Liao, Tsinghua University (China)

Yulin Xi, Beijing Hamamatsu Photon Techniques (China)

General Secretary

Xianfeng Zhu, China Instrument and Control Society (China) 
Administrative Vice General Secretary

Yu-nan Sun, Beijing Institute of Technology (China)

Vice General Secretaries

Wei Xue, Beijing Institute of Technology (China)

Qun Hao, Beijing Institute of Technology (China)

Yuejin Zhao, Beijing Institute of Technology (China)

Cunlin Zhang, Capital Normal University (China)

Local Organizing Committee

Changming Zhao, Beijing Institute of Technology (China)

Yumei Wen, Chongqing University (China)

Hongda Chen, Institute of Semiconductors, CAS (China)

Shangzhong Jin, China Jiliang University (China)

Zhiping Zhou, Peking University (China)

Xuping Zhang, Nanjing University (China)

Libo Yuan, Harbin Engineering University (China)

Chunqing Gao, Beijing Institute of Technology (China)

Shiqiao Qin, National University of Defense Technology (China)

Tian Lan, Beijing Institute of Technology (China)

Cuiling Li, Beijing Institute of Technology (China)

Liquan Dong, Beijing Institute of Technology (China) 


\title{
Conference Committee
}

\author{
Conference Chairs
}

Guangming Shi, Xidian University (China)

Xuelong Li, Xian Institute of Optics and Precision Mechanics of Chinese Academy of Sciences (China)

Bormin Huang, University of Wisconsin-Madison (United States)

Program Committee

Yun Raymond Fu, Northeastern University (United States)

Zhu Han, University of Houston (United States)

Weisi Lin, Nanyang Technological University (Singapore)

Xiaowei Shao, The University of Tokyo (Japan)

Ling shao, The University of Sheffield (United Kingdom)

Dacheng Tao, University of Technology, Sydney (Australia)

Xiaogang Wang, The Chinese University of Hong Kong (Hong Kong, China)

Feng Wu, University of Science and Technology of China (China)

Xiaolin Wu, McMaster University (Canada)

Yi Niu, Xidian University (China)

Session Chairs

$1 \quad$ Imaging Quality Evaluation and Improvement

Junwei Han, Northwestern Polytechnical University (China)

2 Novel Imaging Techniques

Junwei Han, Northwestern Polytechnical University (China)

3 Pattern Recognition

Junwei Han, Northwestern Polytechnical University (China)

$4 \quad$ System Design and Applications

Junwei Han, Northwestern Polytechnical University (China)

5 Remote Sensing and Weapons

Junwei Han, Northwestern Polytechnical University (China) 
Proc. of SPIE Vol. 9622 962201-12

Downloaded From: https://www.spiedigitallibrary.org/conference-proceedings-of-spie on 26 Apr 2023 Terms of Use: https://www.spiedigitallibrary.org/terms-of-use 


\section{Introduction}

Optical imaging and processing technology are widely applied in scenarios from remote sensing telescope, to medical microscope; from military surveillance to common mobile devices. Any development of optical imaging and processing is promoted by researchers from divergent fields like physics, mathematics, signal processing, etc. OIT'2015-Optical-electronic Imaging and Processing Technology conference is a well-organized platform for gathering researchers with different backgrounds, sharing their ideas, and inspiring new creations.

For this conference, we received more than 80 manuscripts. After serious peer review of every submission, we accepted 61 papers, 30 for oral presentation and 31 for poster. The papers cover a wide range in novel imaging techniques including multi-spectrum imaging, infrared thermal imaging, ultrasonic endoscopic imaging, etc. You may find how to use the fantastic theory like compressive sensing to improve the current imaging system. The papers also cover divergent image processing techniques and system calibration, including quality assessment, image super-resolution, enhancement, pattern recognition, artificial intelligence, and their military, medical, industrial, and consumer electronic applications. You will not only find theoretical improvements in these fields, but also elegant ideas such as the use of optical imaging and processing techniques to aid in surgery or weapon control. By all accounts, we think that this conference was very impressive and successful. We would like to take this opportunity to thank all participants for their great contributions.

\section{Guangming Shi Xuelong Li Bormin Huang}


Proc. of SPIE Vol. 9622 962201-14

Downloaded From: https://www.spiedigitallibrary.org/conference-proceedings-of-spie on 26 Apr 2023 Terms of Use: https://www.spiedigitallibrary.org/terms-of-use 


\title{
Sponsors and Cooperating Organizations
}

\author{
Sponsored by \\ CIS—China Instrument and Control Society (China) \\ SPIE \\ Cooperating Organizations \\ Opto-Electronic-Mechanic Technology and System Integration Chapter, CIS \\ (China) \\ Committee on Optoelectronic Technology, China Optical Society (China) \\ Optical Instrument Chapter, CIS (China) \\ Committee on Optics, China Ordnance Society (China) \\ Beijing Institute of Technology (China) \\ Tianjin University (China) \\ Zhejiang University (China) \\ Tsinghua University (China) \\ Nankai University (China) \\ Capital Normal University (China) \\ Nanjing University (China) \\ Shanghai Jiao Tong University (China) \\ Beijing University of Posts and Telecommunications (China) \\ Chongqing University (China) \\ University of Shanghai for Science and Technology (China) \\ Beijing Hamamatsu Photon Techniques Inc. (China) \\ Instrument Society of America (United States) \\ Institute of Measurement and Control (United Kingdom) \\ Hong Kong Institution of Engineers (Hong Kong, China) \\ The Society of Measurement and Control (Japan)
}


Proc. of SPIE Vol. 9622 962201-16

Downloaded From: https://www.spiedigitallibrary.org/conference-proceedings-of-spie on 26 Apr 2023 Terms of Use: https://www.spiedigitallibrary.org/terms-of-use 